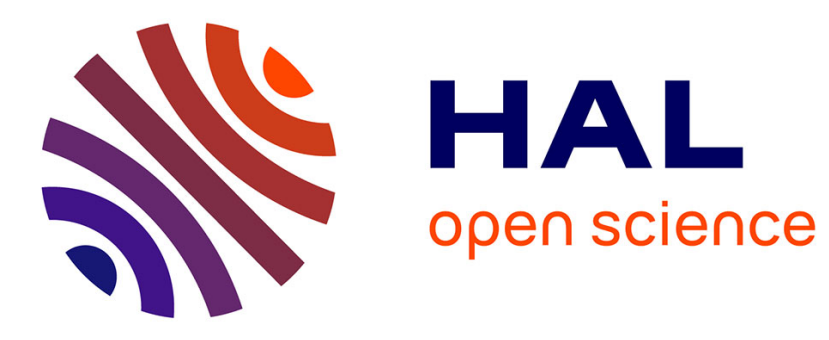

\title{
From colloidal-silica sols to aerogels and xerogels
}

\author{
M. Foret, A. Chougrani, R. Vacher, J. Pelous
}

\section{To cite this version:}

M. Foret, A. Chougrani, R. Vacher, J. Pelous. From colloidal-silica sols to aerogels and xerogels. Journal de Physique IV Proceedings, 1992, 02 (C2), pp.C2-135-C2-139. 10.1051/jp4:1992216 . jpa00251287

\section{HAL Id: jpa-00251287 https://hal.science/jpa-00251287}

Submitted on 1 Jan 1992

HAL is a multi-disciplinary open access archive for the deposit and dissemination of scientific research documents, whether they are published or not. The documents may come from teaching and research institutions in France or abroad, or from public or private research centers.
L'archive ouverte pluridisciplinaire HAL, est destinée au dépôt et à la diffusion de documents scientifiques de niveau recherche, publiés ou non, émanant des établissements d'enseignement et de recherche français ou étrangers, des laboratoires publics ou privés. 


\title{
From colloidal-silica sols to aerogels and xerogels
}

\author{
M. FORET, A. CHOUGRANI, R. VACHER and J. PELOUS
}

L.S.M.V. (URA 1119), Case Courrier 069, Université Montpellier II, Sciences et Techniques du Languedoc, Place E. Bataillon, 34095 Montpellier Cedex 5, France

\begin{abstract}
-
By destabilization of quasi-monodisperse silica sols, fractal clusters can be obtained. Solvent evacuation gives a porous solid with fractal structure. Structural investigations of these colloidal aerogels by small-angle neutron scattering are presented, and compared to similar observations in concentrated sols and xerogels.

An investigation of the vibrational modes of these materials by inelastic neutron scattering gives clear evidence of a strong non-Debye contribution in the low-frequency regime.
\end{abstract}

Introduction.

Silica gels and aerogels are known to be excellent model-materials for the study of fractal inhomogeneous media [1]. They can be prepared under various physical and chemical conditions leading to strongly different microstructures. Small-angle scattering techniques using neutrons or $X$-rays have proven to be well suited for investigating these differences and to characterize the geI structure [2,3]. In this paper we present small-angle neutron scattering (SANS) data on gels derived from the destabilization of colloidal silica sols. The structural differences of a broad set of samples (aerogel, xerogel, sols) are investigated quantitatively by comparing their scattering profiles. Preliminary results of an investigation of the vibrational dynamics by inelastic neutron scattering are also presented for one of these "colloidal" aerogels.

Sample preparation and characterization.

Commercial silica solutions (Ludox manufactured by E.I. Dupont de Nemours and $c o$ ) are destabilized by decreasing the pH-value of the aquasol. After gelation and subsequent solvent exchange, wet gels are either supercritically dried to obtain aerogels or dried in ambient conditions to form xerogels. The supercritical drying, which preserves the fine structure of the original wet gel, allows to produce highly porous samples with densities in the range of $100-300 \mathrm{~kg} \cdot \mathrm{m}^{-3}$ depending on the initial silica concentration. In 
contrast, the classical drying leads to samples with a more compact structure and a macroscopic density of about half the silica density. Two kinds of sol which differ by their particle size, have been studied. In this paper, they are refered to by their commercial name TM and LS. The average radius $x_{0}$ with a dispersity $\Delta r_{0}$ of the spherical colloidal particles have been measured from transmission electron microscopy experiments [4]. Polydispersity appears much larger for small particles.

Colloidal gels result from the connection of these silica particles into aggregated clusters. The precise knowledge of the structure at the particle scale makes these samples a simple model system for the interpretation of elastic scattering experiments.

Experimental results and discussion.

SANS studies were performed on the PAXE spectrometer at the Laboratoire Léon Brillouin in Saclay, France. A combination of two incident wavelengths and two sample-to-detector distances in order to cover the q-range from $3 \times 10^{-2}$ to $0.3 \mathrm{~nm}^{-1}$, was used.

Figure 1 shows, in a log-log plot, the comparison of SANS profiles for colloidal solutions, xerogels and aerogels prepared from the TM and LS sols. At large $q\left(q \geqslant \pi / r_{0}\right)$, the scattering originates from the surface of the particles. The scattered intensity $I(q)$ then follows the well-known Porod law $I(q) \sim q^{-4}$ for all samples. In addition, smeared oscillations are superimposed to the power law. Their amplitude and width vary with the nature of the sol. In contrast, in the low-q range scattering curves are strongly sample dependent. Indeed, for $q$-values smaller than $\pi / r_{0}$ scattering is dominated by correlation effects between particles.

For the diluted sols the quantitative description of the whole scattering curve can be made by assuming that the silica particles scatter neutrons independently. Thus $I(q)$ is the sum of the intensities scattered by each particle, the so-called form factor $P(q)$, depending only on the shape and the size of the scattering particle [5].

Introducing a dispersity of particle size as a Gaussian distribution of $r_{0}$ with a standard deviation $\delta r_{0}$, allows to fit the upper curves of Fig. 1. The best fits are shown on the figure as solid lines. The same calculated curves, arbitrarily shifted along the vertical axis to overlap the high-q regime of the xerogels and the aerogels are also shown in Fig. 1 . The excellent adjustment in this regime, for all samples in a given serie demonstrates that the shape and the size distribution of the particles remains unchanged from the colloidal solutions to the dry gels.

At low $q$, a small departure from the calculated curves occurs in the diluted sols. This is related to interference effects between adjacent particles, For xerogels, theses interferences are enhanced due to the high particle number density. As a consequence a strong drop of the scattered intensity at small $q$ is observed, resulting in the appearance of a maximum in $I(q)$.

Theoretically, such interferences can be expressed by the Fourier Transform $S(q)$ of the pair correlation function $g(r)$ of individual scatterers. The function $g(r)$ is defined as the probability of finding two 


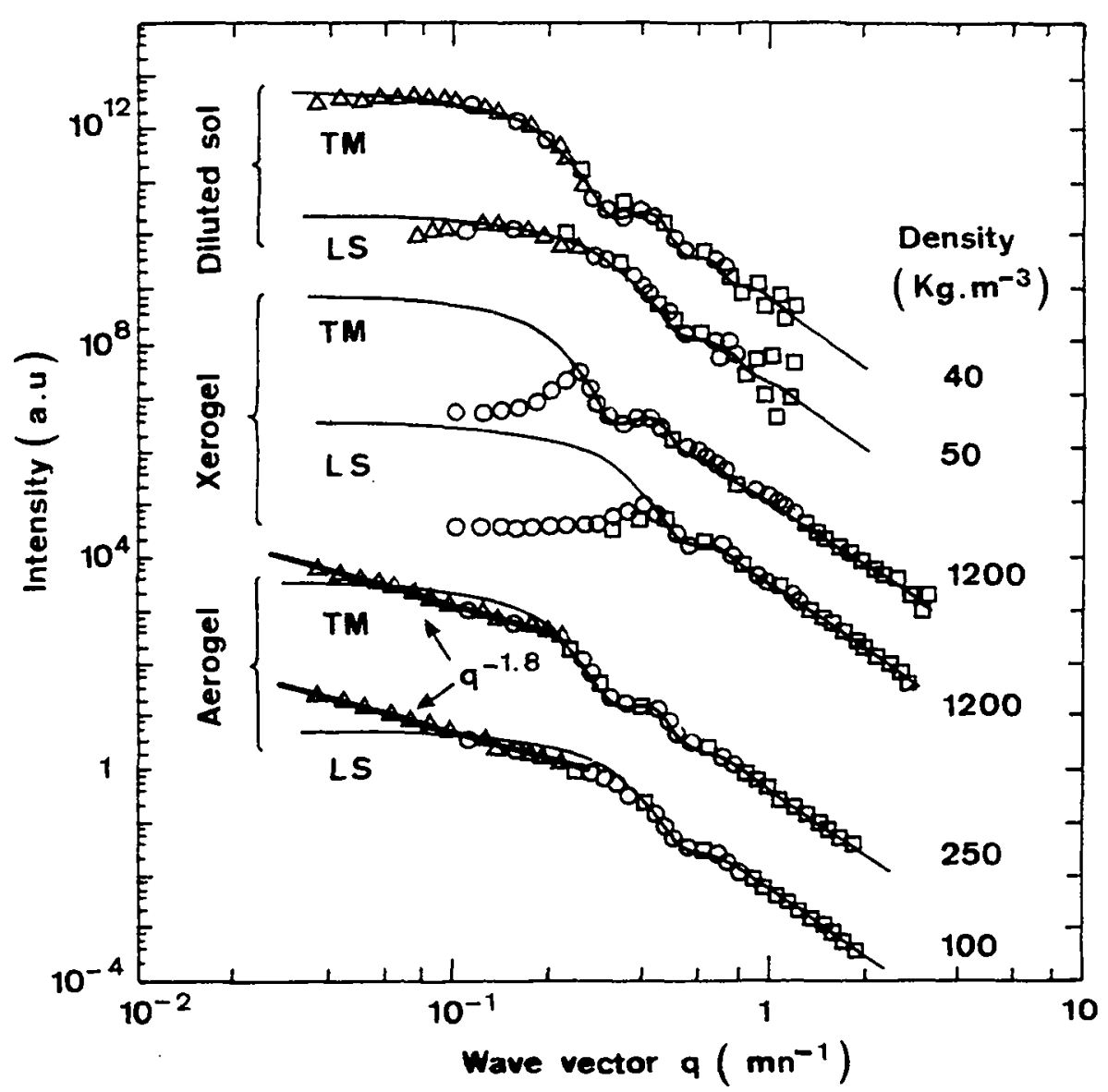

Pig.i - A log-log plot of the scattered intensity $I(q)$ vs $q$ for colloidal solutions xerogels and aerogels prepared from the $M$ and $L S$ sols. Solid lines are fits to the form factor as explained in the text.

particles separated one from the other by a distance $r$. The intensity scattered by an assembly of $\mathrm{N}$ correlated particles can then be written as [6]

$$
I(q)=N \cdot P(q) \cdot S(q)
$$

The correlation peak observed for the xerogels reveals that the particles are not arranged at random but exhibit some short-range ordering.

For the aerogels of low density, the scattered intensity at sma11-q follows the same power law $I(q) \sim q^{-1.8}$ for the two samples, as indicated by the straight lines in Fig. 1. This behavior is the signature of a mass fractal structure, with a fractal (Haussdorf) dimension $D=1.8$. The spatial arrangement of the particles in such fractal aggregates is we11 described by a pair correlation function with the form [7]:

$$
g(r) \propto r^{D-3} \exp (-r / \varepsilon)
$$

Here $\varepsilon$ is a fractal persistence length relative to the crossover from fractal structure to homogeneity at large length-scale. For the two low-density aerogels 


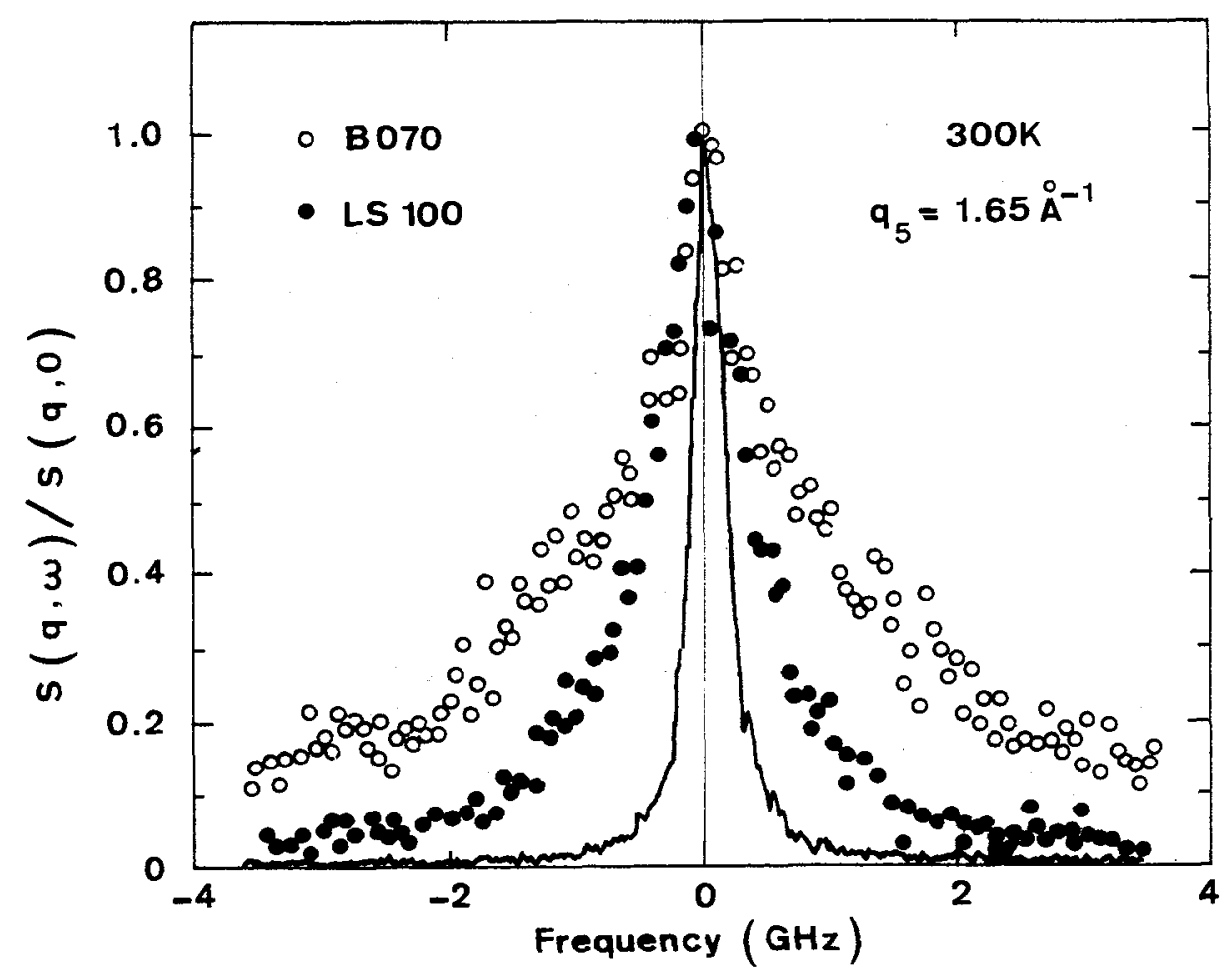

Fig.2 - Normalized inelastic structure factor for a base catalyzed aerogel (B) of density $70 \mathrm{~kg} \cdot \mathrm{m}^{-3}$ and a LS colloidal aerogel of density $100 \mathrm{~kg} \cdot \mathrm{m}^{-3}$. Solid line is the instrumental resolution function taken from Vanadium run at room temperature.

presented here, $\xi$ is outside the length scale investigated experimentally by SANS. Using the proper normalization of $g(r)$ and taking into account the interference effects due to the finite size of the scattering particles allows to fit simultaneously the fractal and Porod regimes and their crossover. Such a fit procedure is developed and discussed in Ref. 4. In this process the fractal dimension $D$ is an adjustable parameter and is found equal within the accuracy of the method to the slope of the straight line $(D=1.8)$ for the two aerogels.

These colloidal aerogels have thus a fractal dimension similar to that previously observed in aerogels prepared from organosilicate precursors under base catalysis [3]. The main differences between the two kinds of samples arise from the size of their elementary particles and their connectivities.

In order to get a better insight on the physical properties of such fractal solids, it is worthwhile to study their vibrational dynamics. This has been done extensively [8] for materials prepared from organosilicates. Vibrational excitations obviously depend on both the structure and the connectivity of the materials. The influence of the sample connectivity can be investigated by comparing the properties of materials having the same fractal dimension, but exhibiting differences in the way the particles are connected at the microscopic and mesoscopic scales.

As shown previously [9], the particle size has a strong influence on the low-frequency spectra in inelastic light scattering. Raman spectra in the $5-50 \mathrm{~cm}^{-1}$ range are dominated by a strong peak whose position and width are 
directly related to the size and the polydispersity of particles, respectively.

We present here preliminary inelastic neutron scattering spectra recorded on the backscattering spectrometer IN10 at the Institut Laue-Langevin in Grenoble. Inelastic structure factors $\mathrm{S}(\mathrm{q}, \omega)$ obtained from the LS colloidal and base-catalysed organosilicate aerogels are shown in Fig. 2.

In this frequency-wavevector domain, it can be shown [10] that

$$
S(q, \omega) \propto G(w) / w^{2},
$$

where $G(\omega)$ is the vibrational density of states. The experimental observation clearly excludes an assignation of the scattering to phonons, as the latter would lead to a frequency independant $S(q, \omega)$. As measured in Raman scattering the lowest-frequency vibrational mode of particles occurs at frequencies of about $100 \mathrm{GHz}$. The above discussion strongly suggests that the observed scattering originates from fracton modes. A comparison of the two curves indicates large differences in the fracton dynamics on the two samples of different connectivity.

\section{References}

[1] Proceedings of the Second International Symposium on Aerogeis, VACHER, $R$, PHALIPPOU, J, PElous, J, WoIGNIER, T, Eds., J. Phys. France, Supp.C4 (1989).

[2] SCHAEFER, D.W, MARTIN, J.E, KEEFER, K.D, Phys. Rev. Lett. 56 (1986) 2199.

[3] VACHER, R, WOIGNIER, T, PELOUS, J, COURTENS, E, Phys. Rev. B 37, (1988) 6500 VACHER, $R$, WOIGNIER, T, PHALIPPOU, J, PELOUS, J, COURTENS, E, J . Non-Cryst. Solids 106, (1988) 161 .

[4] FORET, M, PELOUS, J, VACHER, R, J. Phys. France (1992).

[5] ZERNIKE, F, PRINS, J.A, Z. Phys. 41, (1927) 184.

[6] GUINIER, A, "Théorie et technique de la radiocristallographie" (Dunod, Paris, 1956).

[7] TEIXEIRA, J, in "On Growth and Form" edited by H.E. Stanley and N. Ostrowsky (Martinus Nijhoff, Dordrecht, 1986) p. 145.

[8] VACHER, R, COURTENS, E, CODDENS, G, PELOUS, J, WOIGNIER, T, Phys. Rev. B 39, (1989) 7384. COURTENS, E, LARTIGUE, C, MEZEI, F, VACHER, R, CODDENS, G, FORET, $M$, PELOUS, J, WOIGNIER, $T, Z$. Phys. B 79, (1990) 1. VACHER, $R$, COURTENS, E, CODDENS, G, HEIDEMANN, A, TSUJIMI, Y, PELOUS, J, FORET, M, Phys. Rev. Lett. 65, (1990) 1008.

[9] PELOUS, J, FORET, M, VACHER, R, Proceedings of the Third International Symposium on Aerogels, J. Non-Cryst., in press (1992).

[10] VACHER, R, FORET, M, CODDENS, G, COURTENS, E, Proceedings of the 1991 Annual Meeting of the American Crystallographic Association, in Amer. Cryst. Assoc. Trans. 27 (1991). 